\title{
Relationship between Self Efficacy and Feeling of Reduced Personal Accomplishment among Female Teachers
}

\author{
${ }^{1 *}$ Dr Barnabas E. Nwankwo, ${ }^{2}$ Tobias C. Obi, ${ }^{3}$ Dr. James U. Aboh, \\ ${ }^{4}$ Solomon A Agu \\ ${ }^{1,2}$ Department of Psychology, Caritas University Enugu \\ ${ }^{3,4}$ Department of Psychology, Enugu State University of Science and Technology
}

\begin{abstract}
This study investigated the relationship between self-efficacy and feeling of reduced personal accomplishment among female teachers in South Eastern Nigeria (Abakpa Girls Secondary School). A total of 50 participants comprising of 25 young and 25 old female teachers of Abakpa Girls Secondary School, were used, for the study. The participants who were randomly selected using simple random sampling of which case were within the age range of 25-35 years and above with mean age of 18.8 years and standard deviation of 7.8 years. Two instruments namely; Self-efficacy Scale, ranging from strongly agree to strongly disagree, developed by Barumert (2008) and questionnaire measuring the feeling of reduced personal accomplishment among female teachers, ranging from a few times a year to every day, developed by Bakker (2004) were used in the study. Correlational design was used, pearson product moment correlation co-efficient as statistical test revealed a positive relationship between self-efficiency and feeling of reduced personal accomplishment of (48) $=0.79$ at $P<.05$.
\end{abstract}

\subsection{Background of the Study}

\section{Introduction}

Self-efficacy is defined as the belief in one's capabilities to organize and execute the courses of action required to manage prospective situations. In other words, self-efficacy is person's belief in his or her ability to succeed in a particular situation. Bandura, (1992) described these beliefs as determinants of how people think, behave, and feel. These beliefs begin to form in early childhood as children deal with a wide variety of experiences, tasks, and situations. However, the growth of self - efficacy does not end during youth, but continues to evolve throughout life as people acquire new skills, experiences, and understanding. Self - efficacy can play a major role in how an individual approaches goals, tasks, and challenges which brings us to the sources of self-efficacy. It is said that one of the sources of self-efficacy is mastery experiences which is the most effective way of developing a strong sense of efficacy. Performing a task successfully strengthens on individual's sense of self efficacy. But at the same time failing to deal with a task can undermine and weaken a person's sense of selfefficacy. Social modeling which is another source of self-efficacy, witnessing other people successfully completing a task is another important part of self-efficacy. According to Bandura (1992), "seeing people similar to oneself succeed by sustained effort raises observers' beliefs that they too possess the capabilities, mastery and comparable activities to succeed". In social persuasion which is another source of self - efficacy, people could be persuaded to believe that they have the skills and capabilities to succeed. For instance, consider when someone is getting a verbal encouragement from others, this helps people to overcome self-doubt and focus more on giving their best effort to the task at hand. Psychological response talks about our own responses and emotional reactions to situations which also play an important role in self-efficacy. Moods, emotional state, physical reaction, and stress levels can all impact on how a person feels about their personal abilities in a particular situation. A person who becomes extremely nervous before speaking in public may develop a weak sense of self-efficacy in such situation. It is important to note that it is not the sheer intensity of emotional and physical reactions that is important but rather how they are perceived and interpreted. By learning how to minimize stress and elevate mood when facing difficult or challenging tasks, people can improve their sense of self-efficacy. In conclusion, the main aim of this research work is to know how self-efficacy affects teachers' job. The purpose of study is to determine whether there is any relationship between self-efficacy and feeling of reduced personal accomplishment among female teachers.

\subsection{Statement of the Problem}

There is no doubt that self-efficacy is determined by beliefs, that is why it is said that self-efficacy is the belief in one's capabilities to organize and execute the courses of action required to manage prospective situations. Teachers' perceived self-efficacy affect the quality of instructional transactions and rate of academic progress in 
schools. Teachers operate collectively within an interactive social system rather than as isolates. This belief system of staff creates school cultures that can have vitalizing or demoralizing effects on how well schools function. This research wants to find out if there is any relationship between self-efficacy and feeling of reduced personal accomplishment among female teachers. Bandura (1977) first introduced the construct of selfefficacy. Self-efficacy is within a theory of personal and collective agency that operates in requesting human well-being and attainment. However, the tenets of the self-efficacy components of social cognitive theory have been widely tested in different disciplines and settings and have received support from a growing body of findings from different fields. Self - efficacy beliefs have been found related to clinical problems such as phobias (Bandura, 1983), addiction (Marlatt, Baer, and Quigley, 1995), and depression. However, selfefficacy beliefs have also received increasing attention in educational research, primarily in studies of academic motivation and of self - regulation (Pintrich and Schunk, 1995). In this aspect, self efficacy researchers have focused on three area. Researchers in the first area have explored the link between efficacy beliefs and college major and career choices. This line of inquiry has important implications for counseling and vocational psychology theory and practice, given that findings have provided insights into the career development of young men and women and can be used to develop career intervention strategies. The second area suggests that the efficacy beliefs of teachers' are related to their instructional practices and to various students outcome (Ashton and Webb, 2006). The third area, researchers have reported that student's self-efficacy beliefs are correlated with other motivation constructs and with student's academic performances and achievement. Constructs in these studies have included attributions, goal setting, modeling, problem solving, strategy training, other self-beliefs, expectancy constructs and varied academic performances across dimensions. Self-efficacy's broad application across various domains of behavior has accounted for its popularity in contemporary motivation research (Graham and Weiner, 1996). To that end, the purpose of this study find out if any relationship exist between self efficacy and feeling of reduced personal accomplishments among female teachers in the south eastern nigeria.

\subsection{Hypothesis}

1. There will be a significant relationship between self-efficacy and feeling of reduced personal accomplishment among female teachers.

\subsection{Design/Statistics}

\section{Method}

Based on the two variables observed and measured in a lineally relationship correlation research design was adopted, while persons product moment correlation co-efficient statistics was used for data analysis.

\subsection{Participants}

A total of 50 participants comprising of 25 young and 25 old female teachers of Abakpa Girls Secondary School Enugu were used for the study. The participants who were randomly selected using simple random sampling of which case were within the age range of 25-35 years and a mean age of 18.8 years and standard deviation of 7.8 years.

\subsection{Instrument}

The Self Efficacy questionnaire is a 14 item likert type questionnaire measuring self efficacy among female teachers. It ranged from strongly agree (SA) to Strongly disagree (SD). It was developed by Barument (2008) and re-validated in Nigeria by the researchers with an observed split half reliability coefficient of 0.70 . The second questionnaire measured the feeling of reduced personal accomplishment among female teachers ranging from a few time a year $=6$ point, many times a year $=5$ points, a few times every month $=4$ points, many times every month $=3$ points, a few times every week $=2$ points and every day $=1$ point. Developed by Bakker (2004) which contains 8 items. The researchers in a pilot study using 20 participants observed split-half reliability of 0.73 and 0.70 for $\mathrm{S}$. It has response format of the two questionnaires, for the first questionnaire items are strongly agree 5 points, agree (A) 4 points, undecided (U) 3 points, Disagree (D) 2 points, and strongly Disagree (SD) 1 point.

\subsection{Procedure}

A total of 120 copies of the questionnaire were distributed to selected female teachers for the research. This was done at Abakpa Nike Girls Secondary School, Enugu State, after approvals were given by the authorities of the secondary school. However, only 80 female teachers were screened out of 120 teachers that were recruited for the exercise. Simple random sampling techniques was used to select the sample. Finally when going through it, the researcher found out that 30 copies of the questionnaire were not properly filled and was discarded while 50 copies were correctly filled and used for data analysis. 


\section{Results}

Person product moment correlation co-efficient table and relationship between self-efficacy and feeling of reduced personal accomplishment among female teachers.

\section{Hypothesis 1:}

There still be a significant relationship between self-efficiency and feeling of reduced personal accomplishment among female teachers.

Table 1. Correlation between self efficacy and feeling of reduced personal accomplishment.

\begin{tabular}{|l|l|l|l|l|l|l|l|l|}
\hline $\mathrm{NF}$ & DF & EX & EY & $\mathrm{EX}^{2}$ & $\mathrm{EY}^{2}$ & $\mathrm{EXY}$ & $\mathrm{R}$ & $\mathrm{P}$ \\
\hline 50 & 48 & 1995 & 8475 & 84259 & 81069 & 4088700 & 0.79 & $<.05$ \\
\hline
\end{tabular}

The result of the analysis indicates a correlation between self-efficacy and feeling of reduced personal accomplishment among female teachers since $r$-calculated value of 0.79 is found to be greater than $r$-critical value of a 0.3 at $p<.05$ level of significant, therefore the null hypothesis which states that there will be no relationship between self-efficacy and feeling of reduced personal accomplishment among female teachers was rejected. This indicates that there is a relationship between self-efficacy and feeling of reduced personal accomplishment among female teachers. Using pearson product moment correlation co-efficient. The obtained co-efficient value was 0.79 which suggests a high positive relationship between the two variables studied.

\section{Discussion}

Due to the fact that the computed or calculated value co-efficient has a strong correlation indication, the hypothesis that stated that there will be a statistical significant positive relationship between self-efficacy and feeling of reduced personal accomplishment among female teachers was accepted. Personal accomplishment is positively correlated with self efficacy. High Self efficacy leads more personal accomplishment and low Burnout. This also means that self-efficacy, although seen as an abstract concept among the common methods of improving the feeling of reduced personal accomplishment among female teachers relates with teachers ability to create and adopt a desirable approach to their school work. Factors such as social awareness, teachers' management of relationship significantly affect the academic feeling of reduced personal accomplishment of the teachers. This shows that they play important roles in accomplishment in school work. Factors such as self awareness, self-management and relationship management proposed by Schmitz and Schwarzer (2002) are similar to what Maslach, Schaufeli and Leiter (2001) referred to as the ability to understand, explain and control one's self feelings, his relation with others and ability to solve individual and social problems. Schwarzer and Tang (2000) also called that interpersonal and intrapersonal skills in their study. Interpersonal has to do with how the qualities of self-efficacy help teachers in their socialization in the institutions. Some of these include improved friendships that helps them go about their school work and demands with ease, it also enables them understand the actions and/or reactions of their fellow teachers and their students. Interpersonal skills are shown when teachers understand themselves and explain how they feel and have a suitable frame mind to face their work in school. In the book, working with self-efficacy, Schmitz and Schwarzer (2002) investigated the influence of self-efficacy on working environment and has concluded that a high self -efficacy improves the work feeling of reduced personal accomplishment in different jobs and professional entities. We may lightly establish a link with the assertion of Bandura (1992) that individuals with high self-efficacy can improve organizations feeling of reduced personal accomplishment unlike those with low self-efficacy. Ashton and Webb (2006) also reported that student's self-efficacy beliefs are correlated with other motivation constructs and with students academic accomplishment and achievement.

\subsection{Recommendations}

Considering the importance of influence on self-efficacy on feeling of reduced personal accomplishment. It is recommended that this study be conducted in other countries/states to identify the geographical environment or cultural characteristic, which may alter the finding thereby opening up a new avenue for further research. Further researchers should consider gender differences.

\subsection{Summary and Conclusion}

In summary the result of the analysis showed a positive correlation between self-efficacy and feeling of reduced personal accomplishment among female teachers, since the r-calculated value was found to be quarter than r-critical value, therefore the null hypothesis was rejected while the alternate hypothesis was accepted. This study has shown that the relationship between self-efficacy and feeling of reduced personal accomplishment 
among female teachers are significant and positively associated with the extent of teachers academic accomplishment.

\section{References}

[1]. Ashton \& Webb, Understanding and Preventing Teacher burnout: A source books of international research and practice. (Cambridge: Cambridge University Press, 2006).

[2]. Bakker, Job demand, job resources and then relationship with burnout and engagement: A multi-sample study. Journal of Organizational Behaviour 25, (3), 2004, 293 -315.

[3]. Bandura, Self-efficiency: Toward a Unifying theory of behavioural change. Psychological Review, 84, $1983,191-215$.

[4]. Bandura, Self-efficiency determinants of anticipated fears and calamities Journal of Personality and Social Psychology, 45, 1983, 464-469.

[5]. Bandura, Self-concept and self esteem: A construct differentiation. Child Study Journal. 10(1), 1992, 1-6.

[6]. Y. Barumert, Engagement and emotional exhaustion in teachers, Dose the school context make a difference. Applied Psychology: An international Review, 57, (suppl.)2008, 127-151

[7]. S. Graham, B. Weiner, Dimensions of teachers self-efficacy and relations with strain factors perceived collective teacher efficacy, and teacher burnout Journal of Educational Psychology, 99, 1996, 611 - 625.

[8]. G.A. Marlatt, J.S. Baer, L.A. Quigley, Self efficacy and addictive behaviour. In A. Bandura (Ed.) Self efficacy in changing societies. Pp(289-315). (New York: Cambridge University Press, 1995)

[9]. Maslach, S.W.B, Schaufeli, M.P. Leiter, Job burnout. Annual Review of Psychology, 52, 2001, 397-422.

[10]. P.R. Pintrich, D.H.Schunk,.Motivation in education: Theory, research, and applications. (Englewood Cliffs, NJ: Prentice Hall, 1995)

[11]. R. Schwarzer, C. Tang, Teacher burnout in Hong Kong and gurmany: a cross - cultural validation of the Maslach Burnout inventory. Anxiety, Stress and Coping, 13, 200, 309-326.

[12]. Schmitz, G. S., \& Schwarzer, R. (2002). Individuelle und kollektive Selbstwirksamkeitserwartung von Lehrern [Individual and collective self-efficacy of teachers]. Zeitschrift für Pädagogik, 44. Beiheft: Selbstwirksamkeit und Motivationsprozesse in Bildungsinstitutionen, 192-214. 